\title{
DIETA RICA EM ÁCIDOS GRAXOS POLLIINSATURADOS E VITAMINA A PREVINE ALTERAÇÕES CAUSADAS POR ESTRESSE SOCIAL NA COGNIÇÃO E NA MICROBIOTA
}

Eduarda_Godfried_Nachtigall; PUCRS; eduarda.godfried@gmail.com Gustavo_Provensi; Università degli Studi di Firenze; gustavo.provensi@unifi.it

Scheila_Daiane_Schmidt; PUCRS; scheiladschmidt@hotmail.com Alessia_Costa; Università degli Studi di Firenze; alessia.costa@unifi.it

Patrizio_Blandina; Università degli Studi di Firenze; patrizio.blandina@unifi.it Maria_Beatrice_Passani; Università degli Studi di Firenze; beatrice.passa@unifi.it Jociane_de_Carvalho_Myskiw; PUCRS; jociane_carvalho@hotmail.com Ivan_Izquierdo; PUCRS; ivan.izquierdo@pucrs.br

\section{RESUMO}

Introdução: $\mathrm{O}$ estresse durante a adolescência pode causar ansiedade e déficits cognitivos duradouros. Uma dieta saudável é essencial para o desenvolvimento adequado do cérebro e manutenção de funções cognitivas ideais durante a idade adulta. Os componentes nutricionais interferem na comunidade intestinal de microrganismos, os quais podem afetar a comunicação intestino-cérebro. Objetivo: Investigar os efeitos de uma dieta enriquecida com ácidos graxos poli-insaturados ( $\omega-3$ PUFAs) e Vitamina A no estresse social crônico. Métodos: Ratos Wistar foram divididos em não estressados alimentados com dieta controle (NSCD), estressados alimentados com dieta controle (SCD) e estressados alimentados com dieta enriquecida (SED). Para indução do estresse foi utilizado o protocolo de estresse de instabilidade social. A tarefa de Medo Condicionado ao Contexto, a expressão do fator neurotrófico derivado do cérebro (BDNF) e a composição da microbiota intestinal foram avaliados na adolescência e na idade adulta. Resultados: Grupo SCD apresentou um prejuízo na consolidação da memória de medo e uma diminuição na expressão de BDNF hipocampal na adolescência e na idade adulta. A dieta enriquecida preveniu esses déficits em ambas as idades. Observou-se ainda uma mudança na composição da microbiota entre grupos NSCD e SCD, a qual foi parcialmente prevenida no grupo SED. Conclusão: Os resultados aqui apresentados demonstram os efeitos benéficos da dieta enriquecida, através dos componentes nutricionais, no comprometimento da memória, no declínio da expressão do BDNF e nas alterações na composição da microbiota intestinal induzida pelo estresse, abrindo possíveis novos espaços no campo da neuropsicofarmacologia nutricional.

Palavras-chave: Memória; Dieta; Microbiota; Hipocampo; BDNF. 